\title{
Left and Right Hand Tactile Naming Ability of Everyday Articles by a Young Adult Sample
}

\author{
Hikari Yamashita ${ }^{1}$ \\ ${ }^{1}$ Faculty of Education, Ehime University, Japan \\ Correspondences: Hikari Yamashita, Faculty of Education, Ehime University, Bunkyo-cho 3, Matsuyama \\ 790-8577, Japan. Tel: 81-89-927-9516. E-mail: yamashita.hikari.mz@ehime-u.ac.jp
}

Received: January 9, 2015

Accepted: May 26, 2015 Online Published: August 12, 2015

doi:10.5539/ijps.v7n3p108

URL: http://dx.doi.org/10.5539/ijps.v7n3p108

This study was financially supported by a Grant-in-Aid for Scientific Research (C) from JPSP (No. 15K04130).

\begin{abstract}
Some previous studies have shown that healthy adults can rapidly and accurately identify everyday articles using only tactile information. This study assessed whether laterality effects could potentially influence the tactile object recognition ability for everyday articles. We tested 34 right-handed Japanese young adults who used either their left or right hand. The participants recognized 100 everyday articles without difficulty, regardless of the hand they used. These results might be useful for reference data in assessing patients suspected to have tactile agnosia.
\end{abstract}

Keywords: laterality, left-right asymmetry, tactile object recognition, tactile agnosia

\section{Introduction}

Although vision is the primary sensory modality for humans, touch has been thought as most fundamental means of contact with the world from early infant. Disorders of Tactile Object Recognition (TOR) are not rare at all in patients with brain damage (Caselli, 1991; Valenza, Ptak, Zimine, Badan, Lazeyras, \& Schnider, 2001; Reed \& Caselli, 1994; Reed, Casell, \& Farah, 1996). Those disorders are classified into some categories according to the stage of TOR. Most of those cases originate in incapacity to explore actively the object, or a sensory loss resulting in severely impaired basic somatosensory functions.

Other patients may have deficient TOR because of inability to recognize the shape of objects despite intact sensorimotor functions. This particular form of TOR deficit has been interpreted as a loss of the ability to form the 3-D image of the object from somatosensory system. This type of cases are called "astereognosis" or tactile apperceptive agnosia, but the distinction of both is not clear (Razavi, 2004; Reed \& Caselli, 1994; Reed et al., 1996). The tactile agnosia of another type can form the 3-D image of the object from somatosensory system, but the access to a semantic meaning system is affected. It is called "associative tactile agnosia" or merely "tactile agnosia" (Endo, Miyasaka, Makishita, Yanagisawa, \& Sugishita, 1992; Razavi, 2004; Platz, 1996). Finally, some patients cannot name the object by touching it; however, can name the object when it is presented through another modality. In addition, patients can pantomime the use of a tactile presented object and can categorize objects by their meaning. It is called "tactile aphasia" (Endo et al., 1992; Razavi, 2004).

Although tactile agnosia or tactile aphasia may have provided important clues about neural mechanisms of TOR, there are very few well documented case studies (e.g., Endo et al., 1992; Platz, 1996; Reed \& Caselli, 1994; Reed et al.,1996). To quantitatively evaluate tactile agnosia, reference data from healthy adults on a TOR task using a single hand (left and right hands, respectively) is essential.

Klatzky, Lederman and Metzger (1985) asked 20 college students to identify 100 everyday articles by touch alone. Immediately after visual naming task, blindfolded participants picked up an object and attempted to name it using both hands. They could identify the objects with $95 \%$ accuracy or more. Furthermore, they were quite fast; $94 \%$ of responses were given within five seconds of first touching the object. On the basis of a series of studies, Lederman have pointed out the possibility of some sort of expert system existing in the haptic cognition of everyday articles (Klatzky \& Lederman, 2008; Klatzky, Loomis, Lederman, Wake, \& Fujita, 1993; Lederman \& Klatzky, 1990, 2009). 
Our primary interest is whether laterality could potentially affect TOR ability for everyday articles. Hemispheric specialization for TOR has also been investigated in a great number of studies (Fagot, Lacreuse, \& Vauclair, 1997; Summers \& Lederman, 1990). In general, when meaningless stimuli (e.g., line orientation, dot patterns, mazes, or nonsense shapes) were used, perceptual asymmetries were usually found in favor of the left hand for right-handed persons (e.g., Benton, Harvey, \& Varney, 1973; Benton, Varney, \& Hamsher, 1978; Hatta, 1978; Riege, Metter, \&Williams, 1980; Weener \& Van Blerkom, 1982; Yamamoto \& Hatta, 1980; Young \& Ellis, 1979). This could reflect the better treatment of spatial information by the right hemisphere. Moreover, studies have often reported that men are either more strongly lateralized or more accurate than women (e.g., Dawson, 1981; Kalisch, Kattenstroth, Kowalewski, Tegenthoff, \& Dinse, 2012).

Even so, several studies reported a right-hand advantage for meaningful stimuli such as a letter or a word (Cioffi \& Kandel, 1979; Gibson \& Bryden, 1983; Oscar-Berman, Rehbein, Porfert, \& Goodglass, 1978). However, some findings reported that the left hand is superior for identifying capital letters or names traced in the palms (O’Boyle \& Murray, 1988; O’Boyle, Van Wyhe-Lawler, \& Miller, 1987).

Quite possibly, the right hand could perform better than the left for TOR of everyday articles on the basis of the following three reasons: (i) right-handed persons use everyday articles with their right hands, with some exceptions (e.g., baseball glove, fork, and wristwatch), (ii) everyday articles have characteristics of meaningful stimuli (they have a characteristic form, a name, a concept, and a use, respectively.), and (iii) verbal response (naming) may be more advantageous with the combination of right hand/left hemisphere than with left hand/right hemisphere. However, previous studies have suggested that the texture or complex shape of objects becomes an important clue in TOR (Klatzky \& Lederman, 2008; Klatzky et al., 1993). Therefore, the combination of left hand/right hemisphere is potentially superior to the combination of right hand/left hemisphere for information processing of such stimuli.

In previous studies, only Craddock and Lawson (2009) feature laterality in TOR for everyday articles. They examined the effects of dominant right versus non-dominant left exploration hand on TOR for 48 familiar articles. They did not find a right or left advantage on TOR. Participants could identify articles correctly at $85 \%$ or more. A problem with their research was treating the hand used as a within subject factor. Because the same participants conducted TOR tasks with both hands, there is the risk that the hand-use order and contralateral priming influenced TOR performance. Furthermore, participants in their study had been read the list of items to be used in the tactile object naming.

If the results are too high unfairly their effects, it is inappropriate as reference data of tactile object naming according to right or left hand in healthy adults.

In this study, we examined differences of dominant right versus non-dominant left hand in tactile object naming for everyday articles, with the hand (right and left) used as a between-subjects factor. Furthermore, neither prior visual presentation nor presentation of the object name list was performed, but the pure tactile naming was carried out. The results are expected to become reference data in the clinical study of TOR disorders. Finally, since a variety of studies reported stronger laterality effects in men with respect to women in the tactile modality (e.g., Dawson, 1981; Kalisch et al., 2012; Lenhart \& Schwartz, 1983), possible sex diffrence also explored additionally.

\section{Method}

\subsection{Participants}

Twenty-eight right-handed university students (14 women, 14 men) and 6 clinical staff in a rehabilitation center ( 2 women, 4 men) volunteered for the study (mean age of 23.2 years [SD: 4.2, Range: 18-34]). Right-handedness was determined using the H.N. Handedness Inventory (HNI). HNI consists of 10 items regarding hand preference for daily activities, which is widely used in Japanese handedness-related studies (Hatta \& Nakatsuka, 1975). HNI gives plus one point when the right hand is used, minus one point when the left hand is used, and 0 points when both hands are used in nearly equal proportion. Therefore, the handedness score of HNI ranges from -10 to +10 . The criterion of right-handedness is used when the score is $>+7$.

Each participant was randomly assigned to one of two sex-homogeneous groups, each with 9 men and 8 women, on the basis of the hand to be used in the haptic identification task: left hand (mean age $=23.1$ years, $\mathrm{SD}=4.2$ ) and right hand (mean age $=23.2$ years, $\mathrm{SD}=4.2$ ). All participants gave written informed consent. All the procedures in this study conformed to the code of ethics and conduct of the Japanese Psychological Association.

\subsection{Material}

The stimuli were 100 everyday articles in 10 categories (daily necessities, toys, clothing, foods, office supplies, 
tools, kitchen supplies, ornaments, sports gear, and toiletries. They were selected with the criteria of having no odor or sound clues and being operable with a single hand. Many stimuli duplicated those used in Klatzky et al. (1985).

\subsection{Procedures}

Participants were seated at a table covered with a towel to prevent noise. A membrane type deodorizer (Eecozoa Taru) to control a smell was attached to the ceiling near the table. They were blindfolded and given earphones emitting white noise to mask any acoustic clues. The participants' heads were stabilized on a chinrest clamped to the table, and they responded verbally to a microphone that triggered a voice key (Takei Scientific Instruments, Japan) to measure the response time.

For each trial, an experimenter set an object on the table and tapped the participant's hand. The participant then stretched out a hand (left or right, according to subject group) and picked up the object. When the participant touched the stimulus, the experimenter remotely switched on the digital timer (Takei Scientific Instruments), which terminated with the participant's voice response. The participant's task was to name the object aloud as quickly as possible without making errors. There was a 60 -s time limit for each trial. The order of objects was randomly changed for each participant. After the haptic identification task, each stimulus was visually presented to the participants, and they were instructed to name it aloud, to check for difficult or unknown objects. The trials were all video recorded to measure response time by stopwatch in case the voice key malfunctioned.

\subsection{Data Analysis}

The principal dependent variables were the correct response rate of tactile naming and the response time for correct responses. The mean correct response rate was analyzed by a 2 (hand used) $\times 2$ (sex) two-way ANOVA. Additionally, we compared the number of correct answers by participants of both the left- and right-hand groups for each of 100 articles using the Chi-square test. The response time for correct response was analyzed by a 2 (hand used) $\times 2$ (sex) two-way ANOVA. These analyses were performed with SPSS for Windows (version 15.0J).

\section{Results}

\subsection{Correct Response Rate}

The mean correct response rate for each two-way group is shown in Figure 1. These results show a correct response rate of approximately $90 \%$ regardless of sex and hand used. An ANOVA showed no significant main effect of hand used $\left[\mathrm{F}(1,30)=1.097, \mathrm{p}=.303, \eta_{\mathrm{p}}{ }^{2}=0.035\right]$ or $\left.\operatorname{sex}(1,30)=0.659, \mathrm{p}=.423, \eta_{\mathrm{p}}{ }^{2}=0.021\right]$. Moreover, the interaction between hand used and sex was not significant $\left[\mathrm{F}(1,30)=0.100, \mathrm{p}=0.754, \eta_{\mathrm{p}}{ }^{2}=\right.$ 0.003]. Table 1 shows percent corrects for each article according to hand used groups (each $n=17$ ) and total participants $(n=34)$. Since the main effect and interaction of sex was not significant, men and women have been included in this analysis. The number of everyday articles that all 34 participants named correctly was 49 of 100 . We can determine these articles in particular as readily identifiable. Rice (38.2\%) had the lowest percentage of correct responses. This adopted categories is merely for convenience of experiment, but small articles and clothing seemed difficult to identify. Although the Chi-square test performed for all of the 100 articles, no articles showed a difference in percent correct between the right and left hands.

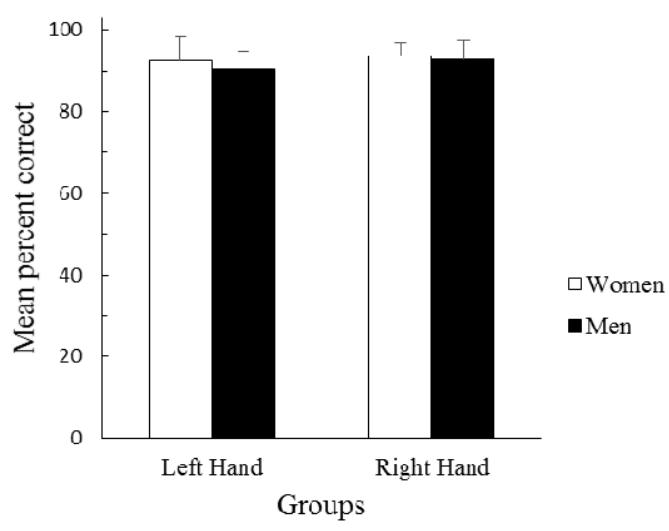

Figure 1. Mean and standard deviations of correct response rate in each group 
Table 1. Percent corrects for each article according to hand used groups and total participants

\begin{tabular}{|c|c|c|c|c|c|c|c|c|c|}
\hline \multirow[b]{3}{*}{ Category } & \multirow[b]{3}{*}{ Articles } & \multicolumn{2}{|c|}{ Groups } & \multirow{3}{*}{$\begin{array}{c}\text { Total } \\
(n=34)\end{array}$} & \multirow[b]{3}{*}{ Category } & \multirow[b]{3}{*}{ Articles } & \multicolumn{2}{|c|}{ Groups } & \multirow{3}{*}{$\begin{array}{c}\text { Total } \\
(n=34)\end{array}$} \\
\hline & & Left & Right & & & & Left & Right & \\
\hline & & $(n=17)$ & $(n=17)$ & & & & $(n=17)$ & $(n=17)$ & \\
\hline \multirow[t]{10}{*}{ Daily Necessaries } & wallet & 100 & 100 & 100 & Tools & hammer & 100 & 100 & 100 \\
\hline & key & 100 & 92.9 & 96.4 & & pliers & 78.6 & 100 & 89.3 \\
\hline & rubber band & 100 & 100 & 100 & & brush & 92.9 & 78.6 & 85.7 \\
\hline & ashtray & 100 & 100 & 100 & & sandpaper & 100 & 92.9 & 96.4 \\
\hline & umbrella & 100 & 100 & 100 & & scissors & 100 & 100 & 100 \\
\hline & magnifying glass & 100 & 100 & 100 & & screw & 92.9 & 92.9 & 92.9 \\
\hline & candle & 64.3 & 64.3 & 64.3 & & screwdriver & 100 & 100 & 100 \\
\hline & newspaper & 71.4 & 92.9 & 82.1 & & nail & 92.9 & 100 & 96.4 \\
\hline & safety pin & 71.4 & 64.3 & 67.9 & & cutter knife & 100 & 100 & 100 \\
\hline & matches & 92.9 & 100 & 96.4 & & plane & 64.3 & 71.4 & 67.9 \\
\hline \multirow[t]{10}{*}{ Toys } & balloon & 100 & 100 & 100 & Kitchen Supplies & knife & 100 & 85.7 & 92.9 \\
\hline & crayon & 50.0 & 64.3 & 57.1 & & spoon & 100 & 100 & 100 \\
\hline & playing cards & 100 & 100 & 100 & & fork & 100 & 100 & 100 \\
\hline & toy pistol & 92.9 & 100 & 96.4 & & dish & 100 & 100 & 100 \\
\hline & recorder & 100 & 100 & 100 & & coffee cup & 100 & 100 & 100 \\
\hline & harmonica & 85.7 & 92.9 & 89.3 & & sponge & 92.9 & 100 & 96.4 \\
\hline & Teddy bear & 100 & 100 & 100 & & scrubbing brush & 100 & 100 & 100 \\
\hline & bouncy balls & 71.4 & 92.9 & 82.1 & & toothpick & 92.9 & 100 & 96.4 \\
\hline & spinning top & 100 & 100 & 100 & & can opener & 100 & 92.9 & 96.4 \\
\hline & flying discs & 64.3 & 78.6 & 71.4 & & ladle & 100 & 100 & 100 \\
\hline \multirow[t]{10}{*}{ Clothing } & belt & 100 & 100 & 100 & Sport Gears & baseball ball & 92.9 & 100 & 96.4 \\
\hline & gloves & 92.9 & 100 & 96.4 & & tennis racket & 100 & 100 & 100 \\
\hline & scarf & 64.3 & 42.9 & 53.6 & & baseball bat & 100 & 100 & 100 \\
\hline & shoelace & 92.9 & 85.7 & 89.3 & & baseball glove & 100 & 92.9 & 96.4 \\
\hline & socks & 71.4 & 85.7 & 78.6 & & shuttlecock & 92.9 & 100 & 96.4 \\
\hline & sweater & 57.1 & 78.6 & 67.9 & & golf ball & 100 & 100 & 100 \\
\hline & $\mathrm{T}$-shirt & 50.0 & 78.6 & 64.3 & & whistle & 100 & 100 & 100 \\
\hline & necktie & 78.6 & 92.9 & 85.7 & & sports shoes & 100 & 100 & 100 \\
\hline & knit cap & 100 & 100 & 100 & & tennis ball & 100 & 100 & 100 \\
\hline & button & 100 & 100 & 100 & & jump rope & 100 & 100 & 100 \\
\hline \multirow[t]{10}{*}{ Foods } & carrot & 78.6 & 92.9 & 85.7 & Ornaments & pierced earring & 50.0 & 57.1 & 53.6 \\
\hline & biscuit & 100 & 78.6 & 89.3 & & ring & 100 & 92.9 & 96.4 \\
\hline & onion & 100 & 100 & 100 & & tie & 85.7 & 100 & 92.9 \\
\hline & potato & 100 & 100 & 100 & & wrist watch & 100 & 100 & 100 \\
\hline & green pepper & 100 & 100 & 100 & & glasses & 100 & 100 & 100 \\
\hline & rice & 35.7 & 35.7 & 35.7 & & mobile phone & 100 & 92.9 & 96.4 \\
\hline & tea bag & 78.6 & 71.4 & 75.0 & & bracelet & 78.6 & 71.4 & 75.0 \\
\hline & apple & 100 & 100 & 100 & & credit card & 50.0 & 85.7 & 67.9 \\
\hline & banana & 100 & 100 & 100 & & amulet & 100 & 100 & 100 \\
\hline & lemon & 85.7 & 85.7 & 85.7 & & lighter & 100 & 100 & 100 \\
\hline \multirow[t]{10}{*}{ Office Supplies } & pencil & 100 & 100 & 100 & Toiletries & toothbrush & 100 & 100 & 100 \\
\hline & eraser & 100 & 100 & 100 & & comb & 100 & 100 & 100 \\
\hline & compass & 92.9 & 92.9 & 92.9 & & hairbrush & 78.6 & 71.4 & 75.0 \\
\hline & paperclip & 100 & 100 & 100 & & toilet paper & 100 & 100 & 100 \\
\hline & envelope & 100 & 85.7 & 92.9 & & plaster & 85.7 & 92.9 & 89.3 \\
\hline & stamp & 71.4 & 71.4 & 71.4 & & tweezers & 100 & 92.9 & 96.4 \\
\hline & ruler & 100 & 100 & 100 & & cotton swab & 92.9 & 100 & 96.4 \\
\hline & stapler & 100 & 100 & 100 & & nail files & 85.7 & 85.7 & 85.7 \\
\hline & Scotch tape & 100 & 100 & 100 & & bandage & 85.7 & 100 & 92.9 \\
\hline & notebook & 92.9 & 92.9 & 92.9 & & nail clippers & 100 & 100 & 100 \\
\hline
\end{tabular}

\subsection{Correct Response Time}

The mean correct response time of each two-way group is shown in Figure 2. An ANOVA showed no significant main effect of hand used $\left[\mathrm{F}(1,30)=1.377, \mathrm{p}=0.250, \eta_{\mathrm{p}}{ }^{2}=0.044\right]$ or $\operatorname{sex}\left[\mathrm{F}(1,30)=0.457, \mathrm{p}=0.504, \eta_{\mathrm{p}}{ }^{2}=\right.$ $0.015]$. Nor was the interaction between hand used and sex significant $\left[F(1,30)=0.275, p=0.253, \eta_{p}{ }^{2}=0.028\right]$. 


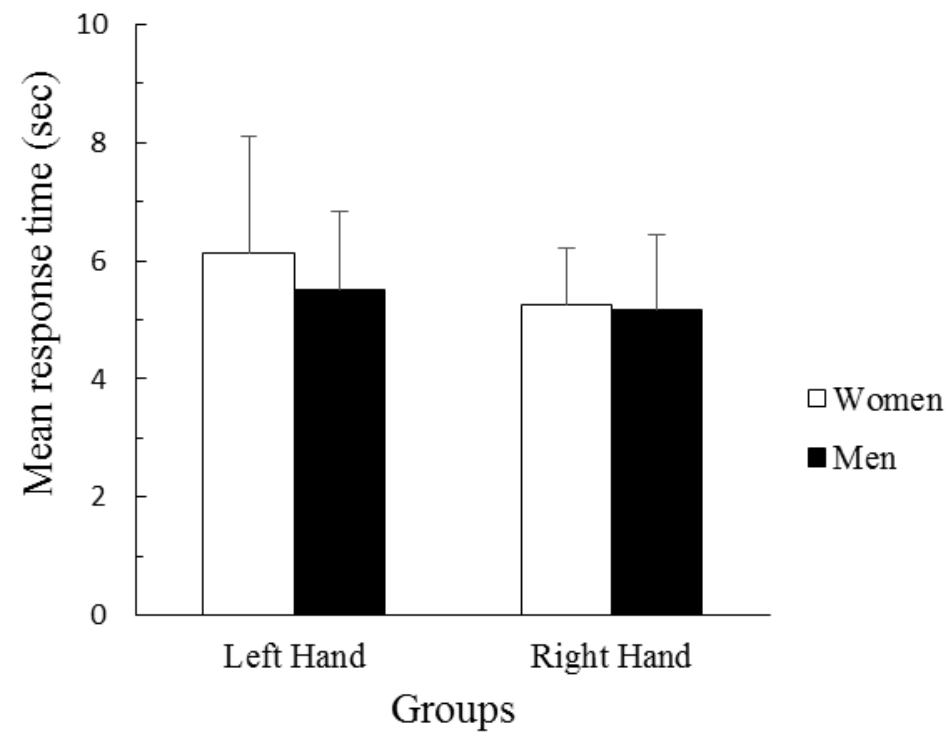

Figure 2. Mean and standard deviations of correct response time of each group

\subsection{Visual Naming}

Finally, on the visual-verbal naming after the haptic identification task, all participants but two could immediately name almost all the stimulus objects. Two participants could not name only one object (a pierced earring and pliers).

\section{Discussion}

We examined the potential laterality of tactile object naming task by letting the two participant groups explore objects, one group with the right hand and one with the left. In this research, neither prior visual presentation nor presentation of the object name list was performed, but the pure tactile naming was carried out. This is because it is the important purpose of this study to estimate the pure ability for tactile object naming in healthy young adults.The results can be summarized as follows: first, these results replicated Klatzky's et al. findings (1985) that, in principle, TOR for everyday articles can be both fast and accurate. Nevertheless, identification accuracy was slightly lower and response time substantially greater than in Klatzky et al. (1985). It is difficult to account for these differences. However, it might influence the participants experienced visual naming before TOR task in their experiment. Another explanation might be a difference in the efficiency of identification with one hand compared to two hands in Klatzky et al. (1985). However, because this experiment did not include a two-handed condition, this explanation cannot be directly confirmed.

The present results also replicated no hand difference in TOR for everyday articles, as was observed in a previous study (Craddock \& Lawson, 2009). Moreover, no differences between women and men were observed. As for percentages of correct responses in particular, no one article showed laterality according to how the participant usually used it. That hemispheric differences exist in tactile information processing has been confirmed in many studies (Fagot et al., 1997; Summers \& Lederman, 1990). So, why did this experiment reveal no differences between right and left hands? Possibly, information-processing efficiency of the left and right hemispheres was balanced by chance in this task. It is also plausible that information from the left hand is better analyzed nonverbally and spatially, but not verbally, whereas information from the right hand is just the opposite. Consequently, the difference between processing through the right or left hand is insignificant. However, this is mere reasoning, and further research is required.

Our present study has several limitations. Only one hand was used at a time in this study. To determine differences in the function of the left hand/right hemisphere and right hand/left hemisphere, the experiment should have had the groups also use both hands. However, this condition adds difficulty to interpreting response time because the manipulation of objects becomes easier with both hands. We are also be interested in the performance of left-handed people and ambidextrous person, could not collect enough data in the research project for a limited time. In addition, to study in earnest possible differences between women and men, a much larger sample is required. Despite these limitations, the present study should contribute to a better understanding 
of the brain mechanism in haptic identification of everyday articles. Our findings can also be useful as reference data for brain-damaged patients with TOR disorders including tactile agnosia. Therefore, further studies using more sophisticated experimental methods, including functional brain imaging, should be conducted to substantiate this study's findings. A functional MRI study suggests that TOR involves a complex network including parietal and insular somatosensory association cortices, as well as occipitotemporal visual areas, prefrontal, and medial temporal supramodal areas, and medial and lateral secondary motor cortices (Reed, Shoham, \& Halgren, 2004). However, they have not been studied difference of hand to be used. By including the left and right hand use a factors of function imaging studies, the elucidation of the role of the left and the right brain in TCR would be expected.

\section{Acknowledgments}

This research was supported by a Grant-in-Aid for Scientific Research (C) from Japan Society for the Promotion of Science (No. 15K04130). There are no known potential conflicts of interest.

\section{References}

Benton, A. L., Harvey, S. L., \& Varney, N. R. (1973). Tactile perception of direction in normal subjects. Neurology, 23, 1248-1250. http://dx.doi.org/10.1212/WNL.23.11.1248

Benton, A. L., Varney, N. R., \& Hamsher, K. de S. (1978). Lateral differences in tactile directional perception. Neuropsychologia, 16, 109-114. http://dx.doi.org/10.1016/0028-3932(78)90049-0

Caselli, R. J. (1991). Rediscovering tactile agnosia. Mayo Clinical Proceedings, 66, 129-142. http://dx.doi.org/ $10.1016 / \mathrm{S} 0025-6196(12) 60484-4$

Cioffi, J., \& Kandel, G. L. (1979). Laterality for stereognostic accuracy of children for words, shapes, and bigrams: A sex difference for bigrams. Science, 204, 1432-1434. http://dx.doi.org/10.1126/science.451575

Craddock, M. I., \& Lawson, R. (2009). Do left and right matter for haptic recognition of familiar objects? Perception, 38, 1355-1376. http://dx.doi.org/10.1068/p6312

Dawson. G. D. (1981). Sex diffcrences in dichaplic processing. Perceptual and Motor Skills, 53, 935-944. http://dx.doi.org/10.2466/pms.1981.53.3.935

Endo, K., Miyasaka, M., Makishita, M., Yanagisawa, N., \& Sugishita, M. (1992). Tactile agnosia and tactile aphasia: Symptomatological and anatomical differences. Cortex, 28, 445-469. http://dx.doi.org/10.1016/ S0010-9452(13)80154-2

Fagot, J., Lacreuse, F., \& Vauclair, J. (1997). Role of sensory and post-sensory factors on hemispheric asymmetries in tactual Perception. In S. Christman (Ed.), Cerebral Asymmetries in Sensory and Perceptual Processing (pp. 469-494). Amsterdam: Elsevier.

Gibson, C., \& Bryden, M. P. (1983). Dichhaptic recognition of shapes and letters in children. Journal of Psychology, 37, 132-143.

Hatta, T. (1978). Functional asymmetry of tactile pattern learning in normal subjects. Psychologia, 21, 283-289.

Hatta, T., \& Nakatsuka, Z. (1975). H. N. Handedness Inventory. In S. Ohno (Ed.), Papers for celebration of the 63th birthday of Prof. Ohnishi (pp. 224-247). Osaka: Osaka City University.

Kalisch, T., Kattenstroth, J. C., Kowalewski, R., Tegenthoff, M., \& Dinse, H. R. (2012). Cognitive and tactile factors affecting human haptic performance in later life. PLoS One, 7, 30420. http://dx.doi.org/ 10.1371/journal.pone. 0030420

Klatzky, R. L., \& Lederman, S. J. (2008). Object recognition by touch. In J. J. Rieser, D. H. Ashmead, F. F. Ebner, \& A. L. Corn (Eds.), Blindness and Brain Plasticity in Navigation and Object Perception (pp. 185-207). New York: Lawrence Erlbaum.

Klatzky, R. L., Lederman, S. J., \& Metzger, V. A. (1985). Identifying objects by touch: An "expert system". Perception \& Psychophysics, 37, 299-302. http://dx.doi.org/10.3758/BF03211351

Klatzky, R. L., Loomis, J., Lederman, S. J., Wake, H., \& Fujita, N. (1993). Haptic identification of objects and their depictions. Perception \& Psychophysics, 54, 170-178. http://dx.doi.org/10.3758/BF03211752

Lederman, S. J., \& Klatzky, R. L. (1990). Haptic classification of common objects: Knowledge-driven exploration. Cognitive Psychology, 22, 421-459. http://dx.doi.org/10.1016/0010-0285(90)90009-S

Lederman, S. J., \& Klatzky, R. L. (2009). Haptic perception: A tutorial. Attention, Perception, \& Psychophysics, 71,1439-1459. http://dx.doi.org/10.3758/APP.71.7.1439 
Lenhart, R. E., \& Schwartz, S. M. (1983). Tactile perception and the right hemisphere: A masculine superiority for imagery coding. Brain and Cognition, 2, 224-232. http://dx.doi.org/10.1016/0278-2626(83)90011-8

O'Boyle, M. W., \& Murray, J. (1988). Hemispheric asymmetry in the identification of four-letter names traced in the right and left palms. Brain and Language, 34, 294-301. http://dx.doi.org/10.1016/0093-934X (88) $90140-\mathrm{X}$

O’Boyle, M. W., Van Wyhe-Lawler, F., \& Miller, D. A. (1987). Recognition of letters traced in the right and left palms: Evidence for a process-oriented tactile asymmetry. Brain and Cognition, 6, 474-494. http:// dx.doi.org/10.1016/0278-2626(87)90141-2

Oscar-Berman, M., Rehbein, L., Porfert, A., \& Goodglass, H. (1978). Dichhaptic hand-order effects with verbal and nonverbal tactile stimulation. Brain and Language, 6, 323-333. http://dx.doi.org/10.1016/0093-934X (78)90066-4

Platz, T. (1996). Tactile agnosia: Casuistic evidence and theoretical remarks on modality specific meaning representations and sensorimotor integration. Brain, 119, 1565-1574. http://dx.doi.org/10.1093/brain/ 119.5.1565

Razavi, M. (2004). Somatosensory System. In M. Rizzo, \& P. J. Eslinger (Eds), Principles and Practice of Behavioral Neurology and Neuropsychology (pp. 305-334). Philadelphia: WB Saunders.

Reed, C. L., \& Caselli, R. J. (1994). The nature of tactile agnosia: A case study. Neuropsychologia, 32, 527-539. http://dx.doi.org/10.1016/0028-3932(94)90142-2

Reed, C. L., Caselli, R. J., \& Farah, M. J. (1996). Tactile agnosia: Underlying impairment and implications for normal tactile object recognition. Brain, 119, 875-888. http://dx.doi.org/10.1093/brain/119.3.875

Reed, C. L., Shoham, S., \& Halgren, E. (2004). Neural substrates of tactile object recognition: An fMRI study. Human Brain Mapping, 21, 236-246. http://dx.doi.org/10.1002/hbm.10162

Riege, W. H., Metter, E. J., \& Williams, M. V. (1980). Age and hemispheric asymmetry in nonverbal tactual memory. Neuropsychologia, 18, 707-710. http://dx.doi.org/10.1016/0028-3932(80)90112-8

Summers, D. C., \& Lederman, S. J. (1990). Perceptual asymmetries in the somatosensory system: A dichhaptic experiment and critical review of the literature from 1929 to 1986. Cortex, 26, 201-226. http:// dx.doi.org/10.1016/S0010-9452(13)80351-6

Valenza, N., Ptak, R., Zimine, I., Badan, M., Lazeyras, F., \& Schnider, A. (2001). Dissociated active and passive tactile shape recognition: A case study of pure tactile apraxia. Brain, 124, 2287-2298. http:// dx.doi.org/10.1093/brain/124.11.2287

Weener, P., \& Van Blerkom, M. (1982). Dichhaptic laterality and field dependence. Brain \& Cognition, 1, 323-330. http://dx.doi.org/10.1016/0278-2626(82)90032-X

Yamamoto, M., \& Hatta, T. (1980). Hemispheric asymmetries in a tactile thought task for normal subjects. Perceptual and Motor Skills, 50, 467-471. http://dx.doi.org/10.2466/pms.1980.50.2.467

Young, A. W., \& Ellis, A. W. (1979). Perception of numerical stimuli felt by fingers of the left and right hands. Quarterly Journal of Experimental Psychology, 31, 263-272. http://dx.doi.org/10.1080/ 14640747908400725

\section{Copyrights}

Copyright for this article is retained by the author(s), with first publication rights granted to the journal.

This is an open-access article distributed under the terms and conditions of the Creative Commons Attribution license (http://creativecommons.org/licenses/by/3.0/). 